\title{
Changes in the Density and Composition of Rhizosphere Pathogenic Fusarium and Beneficial Trichoderma Contributing to Reduced Root Rot of Intercropped Soybean
}

\section{Xiaoli Chang ( $\nabla$ xl_chang14042@sicau.edu.cn )}

Sichuan Agricultural University

Huiting Xu

Sichuan Agricultural University

Li Yan

Sichuan Agricultural University

Dan Zhu

Sichuan Agricultural University

\section{Wei Wang}

Sichuan Agricultural University

Muhammd Naeem

Sichuan Agricultural University

Chun Song

Sichuan Agricultural University

\section{Xiaoling Wu}

Sichuan Agricultural University

\section{Guoshu Gong}

Sichuan Agricultural University

Huabao Chen

Sichuan Agricultural University

Min Zhang

Sichuan Agricultural University

Taiguo Liu

Sichuan Agricultural University

\section{Wanquan Chen}

Sichuan Agricultural University

\section{Wenyu Yang}

Sichuan Agricultural University 


\section{Research Article}

Keywords: Maize-soybean relay strip intercropping, Fusarium root rot, Trichoderm spp., Fusarium spp., Antagonism

Posted Date: November 30th, 2021

DOI: https://doi.org/10.21203/rs.3.rs-1067184/v1

License: (c) (i) This work is licensed under a Creative Commons Attribution 4.0 International License.

Read Full License 


\section{Abstract}

\section{Background}

The dynamic of soil-borne disease is closely related to the rhizosphere microbial communities. Maizesoybean intercropping can suppress soybean root rot as compared to monoculture. However, it is still unknown whether rhizosphere microbial community participates in the regulation of intercropped soybean root rot.

\section{Methods}

In this study, the difference of rhizosphere Fusarium and Trichoderma community was compared between healthy or root-rotted soybean rhizosphere soil from soybean monoculture and maize-soybean intercropping, and the inhibitory effect of potential biocontrol Trichoderma against pathogenic Fusarium were examined.

\section{Results}

The abundance of rhizosphere Fusarium was remarkably different between intercropping and monoculture, while Trichoderma was largely accumulated in healthy rhizosphere soil of intercropping rather than monoculture. Four rhizosphere Fusarium species identified were all pathogenic to soybean but displayed distinct composition and isolation proportion in the corresponding soil types. As the dominant and most aggressive species, F. oxysporum was more frequently isolated in diseased soil of monoculture. Furthermore, of three Trichoderma species identified, T. harzianum dramatically increased in the rhizosphere of intercropping rather than monoculture as compared to $\mathrm{T}$. virens and $\mathrm{T}$. afroharzianum. For in-vitro antagonism test, Trichoderma strains had antagonistic effects on F. oxysporum with the percentage of mycelial inhibition ranging of $50.59 \%-92.94 \%$, and they displayed good mycoparasitic abilities against F. oxysporum through coiling around and entering into the hyphae, expanding along cell-cell lumen and even dissolving cell walls of target fungus.

\section{Conclusion}

These results indicate maize-soybean intercropping significantly increase the density and composition proportion of beneficial Trichoderma to antagonist the pathogenic Fusarium species, thus contributing to the suppression of soybean root rot under intercropping.

\section{Introduction}

Soybean root rot is one of the detrimental soil-borne fungal diseases in soybean production worldwide and can often be infected by several pathogens mainly Fusarium spp. and Phythophthora sojae resulting in severe yield losses by 10\%-60\% (Bandara et al. 2020; Díaz-Arias et al. 2013; Hartman et al. 2015). This disease is remarkably affected by the resistance level of soybean cultivars as well as cropping pattern (Chang et al. 2020; Nelson et al. 1997; Wei et al. 2014; Zhang et al. 2013). In Northeast China, Fusarium 
root rot is very popular because of long-term continuous soybean monoculture and has been recognized as one important limited factor of soybean production (Wei et al. 2014). With the increasing of planting area in Southwest China, this disease has potentially threatened local soybean production (Chang et al. 2018,2020 ). Currently, the control of soybean root rot is mainly dependable of agricultural practices such as crop rotation or intercropping, soil tilling, effective and durable resistant varieties as well as chemical agents (Akamatsu et al. 2019; Gao et al. 2014; Zhang et al. 2013). Although resistance breeding of soybean has largely developed with modern molecular techniques, cost-effective and durable resistant varieties are still lack for application (Nelson et al. 1997; Naeem et al. 2021; Sepiol et al. 2017; Zhang et al. 2013). Chemicals is very helpful to prevent pathogen infection, but it often fails to cure a plant once infection occurs and otherwise sometimes affects beneficial soil microbes following excessive accumulation in soil environment (Naseri 2013, 2014). Recently, biological control has attracted considerable attention to the sustainable management of soybean root rot due to its advantages on balance crop production and agricultural environment protection (Berendsen et al. 2012; John et al. 2010; Wang et al. 2015).

Trichoderma is one genus of fungi in the family Hypocreaceae, which is commonly existing in soil, root and foliar ecosystem (Benitez et al. 2004). Since 1932, T. lignorum was firstly reported to have antagonistic effect on Rhizoctonia solani (Wending 1932), many Trichoderma species such as $T$. harzianum, T. viren, T. asperellum, T. hamatum, T. longibrachiatum and T. koningii, have successively been identified as antagonistic fungi against plant pathogens (Harman et al. 2004; Izquierdo-García et al. 2020), especially soil-borne pathogenic fungi (Anees et al. 2010; Lynch et al. 1991; Lahlali and Hijri 2010; Li et al. 2018). For example, T. harzianum and T. asperellum are effective biological control agents against $F$. oxysporum causing watermelon wilt (Zhang et al. 2020), and T. asperellum isolates significantly suppresses Fusarium tomato wilt (Cotxarrera et al. 2002). Some Trichoderma strains can confer biocontrol either directly by interacting with pathogens via re-parasitism, or by competition for nutrients or root niches, while other strains establish robust and durable colonization of root surfaces and penetrate into the epidermal cells to indirectly induce host resistance mechanism and enhance root growth (Harman et al. 2004; Hermosa et al. 2012). Accordingly, Trichoderma has become among the most extensively studied beneficial fungi for agricultural crop improvement (Abdelrahman et al. 2016) and a few species have already been explored as fungal biocontrol agents (BCA), bio-pesticides or biofertilizers for the biocontrol of the soilborne fungal diseases (Alfiky and Weisskopf 2021).

Accumulating researches indicate that the cropping pattern can affect soil microbial community, change the composition of beneficial and pathogenic microbes and regulate the occurrence of soil-borne disease (Rolfe et al. 2019). In the Radix pseudostellariae rhizosphere, the consecutive monoculture increases the abundance of the pathogenic F. oxysporum but decreases Trichoderma spp. (Chen et al. 2021). Recently, a maize-soybean relay strip intercropping is widely practised in Southwest China, and this cropping pattern is characterized by two-row maize plants strip intercropped with two-to-four rows of soybean which has positive effects on increasing the land equivalent ratio (Yang et al. 2015), improving the soil nutrients and microbe structure (Chen et al. 2017; Song et al. 2020,2021), reducing weeds and diseases in 
the field ( Chang et al. 2020; Su et al. 2018) and increasing crop yield (Du et al. 2018; Liu et al. 2017) as compared to soybean monoculture. This intercropping can also reduce the disease severity of Fusarium root rot and change the population diversity of the pathogenic Fusarium species in diseased soybean roots (Chang et al. 2020). However, the underlying mechanism by this intercropping on regulating soybean root rot is largely unclear.

In the current study, we will focus on rizhosphere microbial communities and their participation in the regulation of soybean root rot in maize-soybean relay stripping intercropping as compared to soybean monoculture, and two aspects were performed: (1) the density of Fusarium and Trichoderma communities were identified and compared from diseased soybean rhizosphere soil and healthy soybean rhizosphere soil of intercropping and monoculture; (2) the antagonistic effects of Trichoderma species on the pathogenic $F$. oxysporum of soybean root rot were examined in vitro. This study will be meaningful for uncovering the rhizosphere microbial regulation of maize-soybean relay strip intercropping on Fusarium root rot and exploring the beneficial Trichoderma strains for the biocontrol of soil-borne diseases

\section{Materials And Methods}

Maize-soybean relay strip intercropping and soybean monoculture were continuously planted since 2012 at Yucheng District, Yaan City, China (29 59"3.17'N, 102 $\left.59^{\prime \prime} 2.57^{\prime} \mathrm{E}\right)$ as described by Chang et al. (2020). This field experiment was designed using the randomized complete block for three replicated experimental plots. Maize cultivar "Denghai605" and soybean cultivar "Nandou12" were selected in the intercropping or monoculture, and all plots were not tilled before sowing to remain soil microbial community.

\section{Collection of soil samples}

At the R2 growth stage of soybean, soil samples were collected from diseased soybean plants displaying root rot and healthy soybean plants in each experimental plot of intercropping (marked as IDR and IHR) and monoculture (marked as MDR and MHR), respectively. The rhizosphere soil was carefully scraped from soybean root hair using a hairbrush after shaking off the loosely attached soil from the soil block. The soil of 9 plants accounting for about $5 \%$ of total plants in each plot were mixed as one sample and kept in an icebox with a sterile polyethylene bag, and then were used for the isolation and identification of Fusarium and Trichoderm species.

\section{Isolation and purification of Fusarium and Trichoderma}

After drying and filtered using a $60-\mu \mathrm{m}$ sieve, Fusarium were isolated from soil smples using sterilized Fusarium-selective medium (PPA, $5 \mathrm{~g} \cdot \mathrm{L}^{-1}$ Tryptone, $1.0 \mathrm{~g} \cdot \mathrm{L}^{-1} \mathrm{KH}_{2} \mathrm{PO}_{4}, 0.5 \mathrm{~g} \cdot \mathrm{L}^{-1} \mathrm{MgSO}_{4}, 1.0 \mathrm{~g} \cdot \mathrm{L}^{-1}$ quintozene, $20.0 \mathrm{~g} \cdot \mathrm{L}^{-1}$ agar) referred to pervious methods (Liu et al. 2008). Rhizosphere soil with different weights $(0.020 \mathrm{~g}, 0.025 \mathrm{~g}, 0.030 \mathrm{~g}, 0.035 \mathrm{~g}, 0.040 \mathrm{~g}, 0.045 \mathrm{~g}$ and $0.050 \mathrm{~g}$ ) were mixed with PPA medium 
poured on $90-\mathrm{mm}$ plates and then incubated at $25^{\circ} \mathrm{C}$ for $5-7 \mathrm{~d}$. The colony number on PPA plates with the proper soil weight were calculated. Pure isolates of Fusarium were obtained through single-spore isolation method and transferred into Potato Dextrose Agar (PDA, $200 \mathrm{~g} \cdot \mathrm{L}^{-1}$ potato, $10 \mathrm{~g} \cdot \mathrm{L}^{-1}$ glucosum anhydricum, and $15 \mathrm{~g} \bullet \mathrm{L}^{-1}$ agar) for further analysis.

Isolation of soil Trichoderm were conducted using dilution-plate method using Trichoderm-selective medium (TSM, glucose $3 \mathrm{~g} \cdot \mathrm{L}^{-1}$, monobasic potassium phosphate $0.9 \mathrm{~g} \cdot \mathrm{L}^{-1}$, magnesium sulfate $0.2 \mathrm{~g} \cdot \mathrm{L}^{-1}$, $1 / 3000(\mathrm{~V} / \mathrm{V})$ rose-bengal $100 \mathrm{~mL} \cdot \mathrm{L}^{-1}$, potassium chloride $0.15 \mathrm{~g} \cdot \mathrm{L}^{-1}$, ammonium nitrate $\mathrm{g} \cdot \mathrm{L}^{-1}$ \agar 20 $\mathrm{g} \cdot \mathrm{L}^{-1}$ ) as described by Elad et al. (1981) with minor revisions. Total $10 \mathrm{~g}$ of soil samples were suspended in $90 \mathrm{ml}$ sterilized water containing $0.5 \%$ Tween-80 and shaken at $25^{\circ} \mathrm{C}, 150 \mathrm{r} \cdot \mathrm{min}^{-1}$ for $40 \mathrm{~min}$. About 1 $\mathrm{mL}$ of soil suspension was then diluted into $10^{-1}, 10^{-2}, 10^{-3}, 10^{-4}$, and $10^{-5}$ with sterilized water. And moreover, $1 \mathrm{~mL}$ diluted soil suspension were mixed with TSM medium and spread on 9-cm Petri plates. All culture plates were incubated at $25^{\circ} \mathrm{C}$ in the darkness for $3-5$ days. Colony number of Trichoderma in different diluted soil suspensions were calculated. For purification, the single spore of the putative Trichoderma colonies was transferred on PDA plates and cultured at $25^{\circ} \mathrm{C}$.

\section{Richness of rhizosphere Fusarium and Trichoderma}

The richness of Fusarium and Trichoderma in different soil samples were calculated using water content

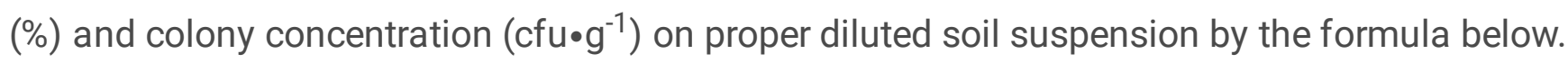

soil water content $(\%)=\frac{\text { fresh soil weight }- \text { dried soil weight }}{\text { dried soil weight }} \times 100$

colony units $\left(c f u \cdot g^{-1}\right.$ dried soil $)=\frac{\text { colony number per plate } \times \text { dilution fold }}{1-\text { soil water content }}$

\section{DNA extraction and PCR amplification}

The mycelia of fungal isolates were collected from 7-day-old isolates on PDA dishes and then grounded in liquid nitrogen with a disposable pellet pestle. Total genomic DNA of all isolates was extracted using a SP Fungal DNA Kit (Aidlab Biotech, Chengdu, China) according to the manufacturer's protocols. The partial sequences of translation elongation factor 1-alpha (EF-1a) and RNA polymerase beta large subunit II (RPB2) were amplified for the identification of Fusarium speciesusing the primer pairs EF1/EF2 (O'Donnell et al. 1998) and RPB2-5f2/RPB2-7cr (O'Donnell et al. 2010,2013), respectively, while ribosomal DNA internal transcribed spacer (rDNA ITS), EF-1 $a$ and RPB2 were amplified using primers ITS1/ITS4 (White et al. 1990), EF-728F/EF1LLErev (Jaklitsch et al. 2005) and fRPB2-5F/fRPB2-7cR (Liu et al. 1999) to identify Trichoderma species. PCR reaction was conducted in a total volume of $25 \mu \mathrm{L}$ containing DNA template $1 \mu \mathrm{L}$, each primer $1 \mu \mathrm{L}(10 \mu \mathrm{M})$, Taq PCR Mastermix (Sangon Biotech, Shanghai, China) $12.5 \mu \mathrm{L}$, and DNase free water $9.5 \mu \mathrm{L}$. The fragments of $r D N A$ ITS were amplified with the conditions of 2 min at $94{ }^{\circ} \mathrm{C}$, followed by 35 cycles of denaturation at $94{ }^{\circ} \mathrm{C}$ for $30 \mathrm{~s}$, annealing at $58{ }^{\circ} \mathrm{C}$ for $30 \mathrm{~s}$, initial 
extension at $72{ }^{\circ} \mathrm{C}$ for $30 \mathrm{~s}$, and remaining at $72{ }^{\circ} \mathrm{C}$ for $10 \mathrm{~min}$. Amplification conditions for $E F-1 \mathrm{a}$ and $R P B 2$ were 5 min at $94{ }^{\circ} \mathrm{C}$, followed by 35 cycles of denaturation at $94{ }^{\circ} \mathrm{C}$ for $30 \mathrm{~s}$, annealing at $55^{\circ} \mathrm{C}$ for $30 \mathrm{~s}$, initial extension at $72{ }^{\circ} \mathrm{C}$ for $1 \mathrm{~min}$, and kept at $72{ }^{\circ} \mathrm{C}$ for $10 \mathrm{~min}$. All primer sequences were listed in Supplementary materials Table S1 and S2. PCR products were checked by $1.5 \%$ agarose gel electrophoresis and sequenced using an ABI-PRISM3730 automatic sequencer (Applied Biosystems, Foster, CA, USA) in Sangon Biotech Co., Ltd. (Shanghai, China)

\section{Phylogenetic analysis}

Amplified sequences of EF-1a and RPB2 gene from candidate Fusarium isolates were blasted on Fusarium MLST databases, while sequences of rDNA ITS, EF-1 $a$ and RPB2 gene from candidate Trichoderma isolates were blasted on the NCBI database. Species of Fusarium and Trichoderma were identified based on the sequence similarity as compared to the reference species. For phylogenetic analysis, sequences of Fusarium and Trichoderma representative isolates, referred isolates and the outgroup isolate were edited and aligned with Clustal X 1.83, and characters were weighed equally. The referred isolates information of Fusarium and Trichoderm were listed in Supplementary materials Table S2.

For Fusarium species, MEGA 5.0 was used to calculate and analyze the differences of their base composition, and phylogenetic trees were constructed using neighbor-joining method based on both EF$1 a$ and $R P B 2$ sequences for Fusarium spp., while those were performed for Trichoderma spp. based on a combination of either rDNA ITS and EF-1a, or rDNA ITS and RPB2, respectively. Clade support was inferred from 1000 bootstrap replicates, and alignment gaps were excluded. Novel sequence data were deposited in GenBank and the alignment in TreeBASE (www.treebase.org).

\section{Pathogenicity test of Fusarium species}

To test whether these Fusarium species identified from soybean rhizosphere are pathogenic, the representative isolates were randomly selected for pathogenicity test on the seedling of soybean cultivar Nandou12 as described by (Chang et al. 2020).

In vitro antagonistic effects of Trichoderm strains on the pathogenic F. oxysporum

For in vitro antagonistic assay, the representative strains of each Trichoderm species were randomly selected to test their antagonistic effects on the mycelium growth of $F$. oxysporum, a strong aggressive pathogen of soybean root rot. Both mycelial plugs of $F$. oxysporum and Trichoderm strains were inoculated on two opposite sides of 90-mm PDA plates with the distance of $75 \mathrm{~mm}$, while only mycelial plug of $F$. oxysporum isolates inoculated on PDA plates were used as controls. Three plates were prepared for each isolates, and three independent experiments were conducted. All plates were incubated at $25{ }^{\circ} \mathrm{C}$ for 5 days in the darkness, and then the distance of F. oxysporum and Trichoderm on PDA plates was recorded. The percentage of mycelial inhibition (PMI) was calculated by the formula below. 
$\mathrm{PMI} \%=\frac{\text { the colony diameter of control }- \text { the colony diameter of treat }}{\text { the colony diameter of control }} \times 100$

For the visualization of hyphae interaction, during confrontation culture, one sterile cover glass was inserted into PDA medium equidistant from Trichoderma and F. oxysporum at an angle of $45^{\circ}$ and cultured at $28^{\circ} \mathrm{C}$ in the dark. When both Trichoderma and F. oxysporum grew on the cover glass, the cover glass was taken out and observed under the compound microscope (Eclipse 80i, Nikon, Japan) and the mycelial interaction between Trichoderma and F. oxysporum was recorded and taken photos.

\section{Data analysis}

All data were recorded and processed using Microsoft office Excel 2010. The data correlation was analyzed using generalized linear model (GLM) with quasipoisson distribution for residuals, and statistical analysis was performed by Duncan's test $(P=0.05)$ with GLM function using SPSS Statistics 20. The composition proportion of Fusarium and Trichoderma spp. were calculated using the percentage of each species in total isolates from the corresponding soil sample, while isolation proportion of each species was evaluated using the percentage of each species in all isolates from four soil samples. The difference of composition and isolation proportion of Fusarium or Trichoderma species in each cropping pattern was analyzed by Fisher's exact test.

Table 1 Population richness of Fusarium and Trichoderma communities in different soil samples from intercropping and soybean monoculture.

\begin{tabular}{lllll}
$\begin{array}{l}\text { Cropping } \\
\text { patterns }\end{array}$ & Soil samples & $\begin{array}{l}\text { Sample } \\
\text { code }\end{array}$ & $\begin{array}{l}\text { Trichoderma richness } \\
\left(\mathrm{cfu} \cdot \mathrm{g}^{-1}\right)\end{array}$ & $\begin{array}{l}\text { Fusarium richness } \\
\left(\mathrm{cfu} \cdot \mathrm{g}^{-1}\right)\end{array}$ \\
\hline Intercropping & $\begin{array}{l}\text { Diseased } \\
\text { rhizosphere soil }\end{array}$ & IDR & $2560.98 \pm 2414.51 \mathrm{ab}$ & $1046.51 \pm 164.44 \mathrm{a}$ \\
\cline { 2 - 5 } & $\begin{array}{l}\text { Healthy rhizosphere } \\
\text { soil }\end{array}$ & IHR & $4404.76 \pm 168.36 \mathrm{a}$ & $329.67 \pm 186.49 \mathrm{~b}$ \\
\hline Monoculture & $\begin{array}{l}\text { Diseased } \\
\text { rhizosphere soil }\end{array}$ & MDR & $523.26 \pm 82.22 \mathrm{~b}$ & $391.62 \pm 12.88 \mathrm{~b}$ \\
\cline { 2 - 5 } & $\begin{array}{l}\text { Healthy rhizosphere } \\
\text { soil }\end{array}$ & MHR & $523.26 \pm 82.22 \mathrm{~b}$ & $458.09 \pm 151.62 \mathrm{~b}$
\end{tabular}

Notes: Different lowercase indicate the significant difference at the level of $\mathrm{P}=0.05$ using SPSS ANOVN.

\section{Results}

Population richness of rhizosphere Fusarium and Trichoderma in response to intercropping and monoculture 
To uncover the influence of cropping patterns on the density of rhizosphere Fusarium and Trichoderma communites associated with soybean root rot, the richness of these two fungi were compared between diseased rhizosphere soil and healthy rhizosphere soil, as well as between intercropping and monoculture. As shown in Table 1, Fusarium was the most richest with $1046.51 \mathrm{cfu} \cdot \mathrm{g}^{-1}$ in diseased rhizosphere soil of intercropping (IDR) among four soil samples, whereas it had no significant difference in two soil types of soybean monoculture. In contrast, Trichoderma richness in two soil types of intercropping (IDR and IHR) was much higher than those of monoculture (MDR and MHR), and meanwhile it was also much richer in healthy rhizosphere soil (IHR) than diseased rhizosphere soil (IDR) of maize-soybean relay strip intercropping but had almost no difference between two soil samples of soybean monoculture. Thus, it is clear that Fusarium richness was significantly declined in healthy rhizosphere soil in two cropping patterns which was followed by the increasing of Trichoderma, and rhizosphere Trichoderma richness is more dramatically affected by cropping pattern while Fusarium richness has also remarkable distinct with respect to the occurrence of root rot under the intercropping.

\section{Species identification of rhizosphere Trichoderma and Fusarium in response to intercropping and monoculture}

In this study, a total of 165 Fusarium isolates were obtained from four soil samples of intercropping and monoculture. Sequence analysis of EF-1 $a$ and RPB2 genes by blasting on the Fusarium MLST database showed that these isolates had more than $98 \%$ sequence identities with those referred isolates of $F$. solani species complex (FSSC), F. oxysporum, F. incarnatum-equiseti species complex (FIESC) and $F$. commune (Supplementary material Table S3), respectively. A phylogenetic tree based on EF-1a and $R P B 2$ was constructed with the representative isolates, referred isolates from $\mathrm{NCBI}$ and the outgroup isolate Nectriaceae sp. (NRRL52754) (Supplementary material Table S2), and results showed that the representative isolates from intercropping were absolutely classified into 3 clades including FSSC, FIESC, and F. oxysporum in this tree constructed based on EF-1 $a$ and RPB2 (Figure 1A), while those isolates from monoculture were claded into FSSC, F. oxysporum and F. commune, respectively (Figure 1B), displaying a distinct species composition of Fusarium between intercropping and monoculture.

For Trichoderma spp., 134 Trichoderma isolates were recovered from rhizosphere soil of diseased and healthy soybean plants in two cropping patterns. Blastn analysis of partial ITS, EF-1a or RPB2 genes on the NCBI database showed that these isolates had more than $95 \%$ sequence identities with T. harzianum, T. virens and T. afroharzianum (Supplementary material Table S4). For phylogenetic analysis in Figure 2, all representative isolates from either intercropping or monoculture were clearly claded intro T. harzianum, $T$. virens, and $T$. afrohazianum, respectively in the ITS/ RPB2-based MP trees with $\geq 99 \%$ the boostrap support value, whereas $T$. harzianum and T. afroharzianum were not totally discriminated in the ITS/EF1a-based phylogenetic trees in both cropping patterns (Supplementary material Figure S1). Thus, Trichoderma isolates from rhizosphere soil were identified as T.virens, T. afroharzianum and $T$. harzianum, and there was no difference in species diversity between intercropping and monoculture. 
Composition and isolation proportion of Fusarium spp. and Trichoderma spp. affected by intercropping and monoculture

The composition and isolation proportion of rhizosphere Fusarium and Trichoderma spp. was further compared between monoculture and intercropping as well as between diseased and healthy soils. As shown in Figure $3 \mathrm{~A}$ and $3 \mathrm{~B}, \mathrm{FSSC}$ had the highest isolation proportion in all soil types that reached up to $88.89 \%$ (40/45) of Fusarium composition and $24.24 \%$ (40/165) of all isolated Fusarium in IDR as compared to $65 \%(28 / 43)$ and $16.97 \%(28 / 165)$ in MDR (Figure 3A and 3B), respectively. F. oxysporum accounted for the second largest proportion in different soil samples and had the highest proportion of $32.56 \%(14 / 43)$ in MDR than that of $8.89 \%(4 / 45)$ in IDR (Figure 1A). The FIESC and F. commune were specifically isolated species in intercropping and monoculture, respectively, with relatively less proportion in corresponding soil samples (Figure 1A and 1B).

In this study, total of three Trichoderma species were obtained from rhizosphere soils of two cropping patterns, but the species composition and isolation proportion varied over the occurrence of root rot as well as cropping pattern (Figure $3 \mathrm{C}$ and $3 \mathrm{D}$ ). Both T. hazianum and T. virens were isolated from all soil types, but $T$. hazianum was the most predominant species of Trichoderma (Figure 3D). The composition proportion of $T$. harzianum was $95.9 \%(71 / 74)$ and $76.2 \%$ (32/42) in IHR and IDR, whereas it was as low as $66.7 \%(6 / 9)$ and $33.3 \%(3 / 9)$ in MHR and MDR, respectively. As the secondary dominant species, $T$. virens in Trichoderma composition was clearly declined in two soil types of intercropping when compared with monoculture, whereas an increase of $T$. afroharzianum appeared in MHR and MDR of monoculture and also in IDR of intercropping. These results indicate that intercropping changes Trichoderma composition and remarkably increases T. hazianum isolation proportion in comparison to monoculture.

\section{The pathogenicity of rhizosphere Fusarium spp. on soybean}

Pathogenicity test of rhizosphere Fusarium species on soybean seedling showed that all four Fusarium species were able to infect soybean roots, and cause stunted, brown, rotted taproots and hair roots but displayed significantly different aggressiveness (Figure 4A). F. oxysporum were the most aggressive among all Fusarium species with disease severity index (DSI) ranging from 35 to 90 (Figure 4B). The DSI of $F$. oxysproum isolates from monoculture were much higher than those from intercropping, with the highest DSI up to 90 (Figure 4B) followed by serious growth inhibition and rotted taproot (Figure 4A). FSSC as the most isolated fungi had moderate aggressiveness with DIS remained around 50 , and there was no significant difference among those isolates from two cropping patterns. In addition, FIESC and $F$. commune separately for intercropping and monoculture were also moderately pathogenic to soybean but different for their aggressiveness.

\section{Inhibition effects of Trichoderma spp. on the pathogenic F. oxysporum of soybean root rot}

As compared to the F. oxysporum control, the representative isolates of three Trichoderma species grew tropically towards F. oxysproum and significantly inhibited mycelial growth of F. oxysporum through 
spatial competition on PDA confrontation culture plates (Figure 5A), and the inhibition response had almost no difference among the same Trichoderma species from intercropping and monoculture. Furthermore, the percentage of mycelial inhibition (PMI) was distinct among three Trichoderma species, but $38.10 \%$ of isolates had the PMI values in the range of $60 \%-70 \%$ (Figure 5 B). T. harzianum isolates showed almost same range of PMI between intercropping and monoculture, whereas $T$. afroharzianum and T. virens had slightly different central PMI values for tested isolates from two cropping patterns. Under two cropping patterns, there was almost no difference in the mean PMI of T. harzianum, which were $58.91 \%$ in intercropping and $57.35 \%$ in monoculture. The mean PMI for $T$. virens was concentrated at $72.0 \%$ in intercropping but it was as high as $60.30 \%$ in monoculture (Figure $5 \mathrm{C}$ ). To be contrast, the mean PMI for $T$. afroharzianum was slightly high up to $73.14 \%$ in intercropping as compare to $66.18 \%$ in monoculture (Figure 5C). This indicates that $T$. virens and $T$. afroharzianum might be also related to $F$. oyxsporum inhibition during rhizosphere fungal interaction with respect to cropping pattern.

To observe the hyphae interaction, T. harzianum grew tropically towards (Figure $6 \mathrm{~A}$ ), attached to the hyphae of F. oxysporum, and coiled around them (Figure 6B). The strains TRB1-15 and TRB1-7 of $T$. virens coiled around the hyphae, formed brown halos at the contact sites (Figure 6C), and some of them directly entered into the lumen of the target fungus (Figure 6D). As shown in Figure 6E, the hyphae of T.afroharzianum has entered into the cell lumen of $F$. oxysporum and expanded along the host hyphae (Figure 6E), and resulted in dissolution of cell walls (Figure 6F). In general, rhizosphere Trichoderma strains displays good mycoparasitic abilities against the pathogenic F. oxysporum of soybean root rot.

\section{Discussion}

Rhizhosphere soil microbes play an important role in the regulating soil-borne diseases that are closely correlated with cropping patterns (Hage-Ahmed et al. 2013; Ren et al. 2008; Zhou et al. 2011). Our previous study proved that maize-soybean relay strip intercropping suppressed the occurrence of soybean root rot and changed the diversity of the pathogenic Fusarium species (Chang et al. 2020). In this study, we further focused on this intercropping effects on rhizosphere Fusarium communities and potential biocontrol Trichoderma communities in association with soybean root rot, and results demonstrated that continuous maize-soybean relay strip intercropping caused a significant accumulation of rhizosphere Trichoderma but reduced the abundance of the pathogenic Fusarium communities, in particular, in healthy soils, whereas consecutive soybean monoculture displayed almost no influence on the density of these two fungi, no matter whether of diseased or healthy rhizosphere soils. This demonstrates that maize-soybean relay strip intercropping is beneficial to induce the accumulation of rhizosphere Trichoderma but not Fusarium communities.

Fusarium species are the dominant pathogens of soybean root rot in Sichuan Province, the Southwest China (Chang et al. 2020), and these Fusarium species often can survive saprophytically and accumulate largely on crop debris, even on or inside cultivated soil, thus serving as primary inocula for soybean infection in rhzosphere microenvironment in the following epidemic year (Beyer et al. 2006). In our study, 
four Fusarium species including F. oyxsporum, FSSC, FIESC and F. commune were identified from all rhizopshere soil samples and all pathogenic to soybean, but the composition and isolation proportion of these Fusarium species in maize-soybean relay strip intercropping were distinct from those in soybean monoculture. Among them, FSSC and $F$. oxysporum were most frequently isolated in both cropping patterns, which is similar to those by Liu et al (Liu et al. 2008). in isolating Fusarium spp. from soybean rhizosphere soil of different rotation systems in black soil area of Northeast China. However, $F$. oxysporum rather than FSSC had the highest isolation proportion from soybean rhizosphere soil in black soil area (Liu et al. 2008), indicating an association of the difference in dominant rizhosphere Fusarium species with soybean ecological planting areas. Compared to Fusarium spp. isolated from diseased soybean root among which FSSC and F. oxysporum were the predominant species in both maize-soybean relay strip intercropping and soybean monoculture (Chang et al. 2018, 2020), the diversity of Fusarium spp. was remarkably lower from diseased and healthy rhizosphere soils of two cropping patterns, indicating that some of Fusarium species causing soybean root rot such as F. gramniearum, $F$. asiaticum, F. proliferatum might come from aboveground inoculums instead of rhizopshere soil-borne pathogens. Moreover, FIESC and F. commune were specific to intercropping and monoculture with relatively low isolation proportion, respectively, which is basically consistent with our previous findings that specifically-isolated F. commune and an low isolation proportion of FIESC from the diseased soybean roots in monoculture rather than maize-soybean relay strip intercropping (Chang et al. 2020). In addition, compared with maize-soybean relay strip intercropping, soybean monoculture did not change the density of rhizosphere Fusarium but dramatically raised the composition proportion and isolation proportion of the most aggressive $F$. oxysporum causing soybean root rot. Therefore, unlike intercropping, more severe root rot in soybean monoculture might depend upon relatively higher proportion of the aggressive F. oxysporum but not upon the higher density of Fusarium communities. This can be supported by another study that continuous soybean cropping increased the population of Fusarium and tended to increase the susceptibility to root rot (Jie et al. 2015).

Beneficial soil microbes have some advantages on suppressing soil-borne pathogenic fungi, promoting plant growth or decomposing plant residues (Setälä and McLean 2004). Trichoderma has widely been recognized as biological control of soil-borne diseases in production (Lahlali and Hijri 2010; Li et al. 2018), but Trichoderma communities is often affected by cropping patterns (Pérez-Brandán et al. 2014). Previous studies found that compared with soybean-maize rotation, continuous soybean monoculture decreased the populations of Trichoderma that may acts as biocontrol alternatives of soil-borne pathogens (Pérez-Brandán et al. 2014)). In contrast, the content of soil Trichoderma increased significantly under the intercropping of sorghum and soybean (Lian et al. 2018). In this study, the density of rhizosphere Trichoderma communities exhibited an increased trend in the intercropping rather than monoculture, and among three species of Trichoderma isolated of two cropping patterns, $T$. harzianum had the highest isolation proportion followed by $T$. virens and $T$. afrohazianum which is basically similar to Wei (2012) that identified three Trichoderma species, mainly T. harzianum and T. virens, and a small amount of $T$. viride, from soybean rhizosphere soil for different rotation years in Heilongjiang Province. In addition, we also observed that these Trichoderma species displayed a good mycoparasitic abilities in the 
antagonist against the pathogenic $F$. oxysporum of soybean root rot, mainly through coiling around the hyphae, entering into the the lumen of the target fungus, expanding into the cell-cell area and finally dissolving the cell wall of host fungus, which have been reported as the typical mycoparasitism of Trichoderma (Alfiky and Weisskopf 2021; Harman et al. 2004). In other studies, Trichoderma virens has been recognized as an aggressive mycoparasite that is capable of competing with pathogens at the site of infection (Djonovic et al. 2007) and also induces JA and SA mediated tomato resistance against Fusarium wilt (Jogaiah et al. 2018). From this point of view, Trichoderma communities are a important group in response to maize-soybean relay strip intercropping as compared to soybean monoculture. This is also proved in previous study by Chen et al (Chen et al. 2021). That expanded monoculture of $R$. peseudostellariae altered Trhicoderma communities in the plant rhizosphere leading to relatively low level of antogonistic microorganisms, and among them T. harzianum ZC51 could inhibit the pathogenic $F$. oxysporum and induce the expression of defense genes. However, several studies have shown that Trichoderma strains with good plate-confrontation effect on pathogens might be not necessarily good, or even no effect, which is predicted to associate with the colonization ability of Trichoderma on plants (Sivan and Chet 1989). Therefore, the antagonistic effect of these Trichoderma strains against $F$. oxysporum causing soybean root rot should be further verified in the actual field production.

\section{Conclusions}

In this study, maize-soybean relay strip intercropping increased the density of beneficial Trichoderma but decreased the pathogenic Fusarium communities (in rhizosphere diseased soil) as compared to soybean monoculture. Intercropping also affected species composition and isolation proportion of rhizosphere Fusarium and Trichoderma communities. The change in the pathogenic Fusarium might be primarily driven by the beneficial Trichoderma strains by re-parasitism interaction. Overall, these findings suggested that maize-soybean relay strip intercropping alters both pathogenic Fusarium and beneficial Trichoderma communities in soybean rizhosphere soil and lead to antagonistic development of the fungal community structure on plant health, which regulates the suppressive effect of this intercropping on soybean root rot.

\section{Declarations}

\section{Acknowledgements}

This work was supported by the National Natural Science Foundation of China (Grant Numbers: 31801685), Agricultural Science and Technology Innovation Program (CAAS-ASTIP), and Science and Technology Plan of Sichuan Province-Key research and development project (2021YFYZ0018). We thank Prof. Minrong Zhang from Nanchong Agricultural Academical Institution and Prof. Huawei Yang from Zigong Agricultural Academical Institution in Sichuan, China for the provision of soybean varieties.

Conflict of interest There are no conflicts of interest in this work. All financial supports are acknowledged in the contribution. This work does not involve any human participants or animals. All authors have 
offered the consent to submission.

\section{References}

Abdelrahman M, Abdel-Motaal F, El-Sayed M, Jogaiah S, Shigyo M, Ito SI et al (2016) Dissection of Trichoderma longibrachiatum-induced defense in onion (Allium cepa L.) against Fusarium oxysporum $\mathrm{f}$. sp. cepa by target metabolite profiling. Plant Sci 246:128-138

Akamatsu H, Kato M, Ochi S, Mimuro G, Matsuoka J, Takahashi M et al (2019) Variation in the resistance of Japanese soybean cultivars to Phytophthora root and stem rot during the early plant growth stages and the effects of a fungicide seed treatment. Plant Pathol J 35:219-233

Alfiky A, Weisskopf L (2021) Deciphering Trichoderma-Plant-Pathogen Interactions for Better Development of Biocontrol Applications. J. Fungi 2021, 7, 61

Anees M, Tronsmo A, Edel-Hermann V, Hjeljord LG, Héraud C , Steinberg C (2010) Characterization of field isolates of Trichoderma antagonistic against Rhizoctonia solani. Fungal Biol 114:691-701

Bandara AY, Weerasooriya DK, Bradley CA, Allen TW , Esker PD (2020) Dissecting the economic impact of soybean diseases in the United States over two decades. PLoS One 15: e0231141

Benitez T, Rincon AM, Limon MC, Codon AC (2004) Biocontrol mechanisms of Trichoderma strains. Int Microbiol 7:249-260

Berendsen RL, Pieterse CMJ , Bakker PAHM (2012) The rhizosphere microbiome and plant health. Trends Plant Sci 17:478-486

Beyer M, Klix MB, Klink H, Verreet J (2006) Quantifying the effects of previous crop, tillage, cultivar and triazole fungicides on the deoxynivalenol content of wheat grain-a review. J. Plant Dis. Prot 113: 241-246

Chang XL, Dai H, Wang DP, Zhou HH, He WQ, Fu Y et al (2018) Identification of Fusarium species associated with soybean root rot in Sichuan Province. Eur. J. Plant Pathol 151:563-577

Chang XL, Yan L, Naeem M, Khaskheli MI, Zhang H, Gong GS et al (2020) Maize/soybean relay strip intercropping reduces the occurrence of Fusarium root rot and changes the diversity of the pathogenic Fusarium species. Pathogens 2020, 9, 211

Chen J, Zhou L, Din IU, Arafat Y, Li Q , Wang J (2021) Antagonistic activity of Trichoderma spp. against Fusarium oxysporum in rhizosphere of Radix pseudostellariae triggers the expression of host defense genes and improves its growth under long-term monoculture system. Front. Microbiol 12:579920

Chen P, Du Q, Liu XN, Zhou L, Hussain S , Lei L et al (2017) Effects of reduced nitrogen inputs on crop yield and nitrogen use efficiency in a long-term maize-soybean relay strip intercropping system. PLoS One 12: e0184503 
Cotxarrera L, Trillas-Gay MI, Steinberg C , Alabouvette C (2002) Use of sewage sludge compost and Trichoderma asperellum isolates to suppress Fusarium wilt of tomato. Soil Biol. Biochem 34:467-476

Díaz-Arias MM, Leandro LF, Munkvold GP (2013) Aggressiveness of Fusarium species and impact of root infection on growth and yield of soybeans. Phytopathology 103:822-832

Djonovic S, Vargas WA, Kolomiets MV, Horndeski M, Wiest A, Kenerley CM (2007) A proteinaceous elicitor $\mathrm{Sm} 1 \mathrm{from}$ the beneficial fungus Trichoderma virens is required for induced systemic resistance in maize. Plant Physiol 145: 875-889

Du JB, Han TF, Gai JY, Yong TW, Sun X, Wang XC (2018) Maize-soybean strip intercropping: Achieved a balance between high productivity and sustainability. J Integr Agric 17: 747-754

Elad Y, Chet I , Henis Y (1981) Biological control of Rhizoctonia solani in strawberry fields by Trichoderma harzianum. Plant Soil 60: 245-254

Gao X, Wu M, Xu R, Wang X, Pan R, Kim HJ et al (2014) Root interactions in a maize/soybean intercropping system control soybean soil-borne disease, red crown rot. PloS one 9:e95031

Hage-Ahmed K, Krammer J , Steinkellner S (2013) The intercropping partner affects arbuscular mycorrhizal fungi and Fusarium oxysporum f. sp. lycopersici interactions in tomato. Mycorrhiza 23: 543550

Harman GE, Howell CR, Viterbo A, Chet I, Lorito M (2004) Trichoderma species-opportunistic, avirulent plant symbionts. Nat. Rev. Microbiol 2:43-56

Hartman GL, Chang HX , Leandro LF (2015) Research advances and management of soybean sudden death syndrome. Crop Prot 73:60-66

Hermosa R, Viterbo A, Chet I, Monte E (2012) Plant-beneficial effects of Trichoderma and of its genes. Microbiology 158:17-25

Izquierdo-García LF, González-Almario A Cotes AM , Moreno-Velandia CA (2020) Trichoderma virens GI006 and Bacillus velezensis Bs006: a compatible interaction controlling Fusarium wilt of cape gooseberry. Sci Rep 2020,10,6857

Jaklitsch WM, Komon M, Kubicek CP, Druzhinina IS (2005) Hypocrea voglmayrii sp. nov. from the Austrian Alps represents a new phylogenetic clade in Hypocrea/Trichoderma. Mycologia 97:1365-1378

Jie WG, Bai L, Yu WJ , Cai BY (2015) Analysis of interspecific relationships between Funneliformis mosseae and Fusarium oxysporum in the continuous cropping of soybean rhizosphere soil during the branching period. biocontrol Sci Techn 25:1036-1051 
Jogaiah S, Abdelrahman M, Tran LSP, Ito SI (2018) Different mechanisms of Trichoderma virensmediated resistance in tomato against Fusarium wilt involve the jasmonic and salicylic acide pathways. Mol. Plant Pathol 19: 870-882

John RP, Tyagi RD, Prévost D, Brar SK, Pouleur S , Surampalli RY (2010) Mycoparasitic Trichoderma viride as a biocontrol agent against Fusarium oxysporum f. sp. adzuki and Pythium arrhenomanes and as a growth promoter of soybean. Crop Prot 29:1452-1459

Lahlali R , Hijri M (2010) Screening, identification and evaluation of potential biocontrolfungal endophytes against Rhizoctonia solani AG3 on potato plants. FEMS Microbiol.Lett 311:152-159

Li JY, Lu CG, Liu T, Liu WC, Su HJ (2018) Trichoderma brevicompactum BF06, a novel strain with potential for biocontrol of soil-borne diseases and promotion of plant growth of cucumber. Chin. J. Biol. Control 34:449-460

Lian TX, Mu YH, Ma QB, Cheng YB, Gao R, Cai ZD et al (2018) Use of sugarcane-soybean intercropping in acid soil impacts the structure of the soil fungal community. Sci. Rep 8:14488

Liu JB, Xu YL , Wei W (2008) Comparing different methods for isolating Fusarium from soybean rhizosphere soil. Soybean Sci 1:106-112

Liu X, Rahman T,Song C, Su B, Yang F, Yong TW et al (2017) Changes in light environment, morphology, growth and yield of soybean in maize-soybean intercropping systems. Field Crops Res 200: 38-46

Liu YJ, Whelen S ,Hall B D (1999) Phylogenetic relationships among ascomycetes: evidence from an RNA polymerse II subunit. Mol. Biol. Evol Molecular Biology and Evolution 16:1799-1808

Lynch JM, Lumsden RD, Atkey PT , Ousley MA (1991) Prospects for control of Pythium damping-off of lettuce with Trichoderma, Gliocladium, and Enterobacter spp.. Biol. Fertil. Soils 12:95-99

Naeem M, Munir M, Li HJ, Raza MA, Song C, Wu XL et al (2021) Transcriptional responses of Fusarium graminearum interacted with soybean to cause root rot. J. Fungi 2021, 7, 422

Naseri B (2014) Bean production and Fusarium root rot in diverse soil environments in Iran. J. Soil Sci. Plant Nutr 14:177-188

Naseri B (2013) Epidemics of Rhizoctonia root rot in association with biological and physicochemical properties of field soil in bean crops. J. Phytopathol 161:397-404

Nelson BD, Hansen JM, Windels CE , Helms TC (1997) Reaction of soybean cultivars to isolates of Fusarium solani from the Red River Valley. Plant Dis 81:664-668

O'Donnell K, Kistler HC, Cigelnik E, Ploetz RC (1998) Multiple evolutionary origins of the fungus causing Panama disease of banana: concordant evidence from nuclear and mitochondrial gene genealogies. 
O'Donnell K, Rooney AP, Proctor RH, Brown DW, McCormick SP, Ward TJ et al (2013) Phylogenetic analyses of RPB1 and RPB2 support a middle Cretaceous origin for a clade comprising all agriculturally and medically important fusaria. Fungal Genet. Biol 52:20-31

O'Donnell K, Sutton DA, Rinaldi MG, Sarver BAJ, Balajee SA, Schroers HJ et al (2010) Internet-accessible DNA sequence database for identifying Fusarium from human and animal infections. J. Clin. Microbiol 48:3708-3718

Pérez-Brandán C, Huidobro J, Grümberg B, Scandiani MM, Luque AG, Meriles JM et al (2014) Soybean fungal soil-borne diseases: a parameter for measuring the effect of agricultural intensification on soil health. Can J Microbiol 60:73-84

Ren LX, Su SM, Yang XM, Xu YC, Huang QW , Shen Q (2008) Intercropping with aerobic rice suppressed Fusarium wilt in watermelon®Soil Biol. Biochem 40: 834-844

Rolfe SA, Griffiths J , Ton J (2019) Crying out for help with root exudates: adaptive mechanisms by which stressed plants assemble health-promoting soil microbiomes. Curr. Opin. Microbiol 49:73-82

Sepiol CJ, Yu J , Dhaubhadel S (2017) Genome-wide identification of chalroot specific GmCHRs and Phytophthora sojae cone reductase gene family in soybean: Insight into resistance. Front Plant Sci 2017, 8,2073

Setälä H , McLean MA (2004) Decomposition rate of organic substrates in relation to the species diversity of soil saprophytic fungi. Oecologia 139:98-107

Sivan A, Chet I (1989) Degradation of fungal cell walls by lytic enzymes from Trichoderma harzianum. J. Gen. Microbiol 135:675-682

Song C, Sarpong CK, Zhang XF, Wang WJ, Wang LF, Gan YF et al (2021) Mycorrhizosphere bacteria and plant-plant interactions facilitate maize Pacquisition in an intercropping system. J. Clean. Prod 314:127993

Song C, Wang QL, Zhang XF, Sarpong CK, Wang WJ, Yong Tw et al (2020) Crop productivity and nutrients recovery in maize-soybean additive relay intercropping systems under subtropical regions in Southwest China. Int. J. Plant Prod 14: 373-387

Su BY, Liu X, Cui L, Xiang B , Yang WY (2018) Suppression of weeds and increases in food production in higher crop diversity planting arrangements: A case study of relay intercropping. Crop Sci 58: 1729-1739

Wang LY, Xie YS, Cui YY, Xu J, He W, Chen HG et al (2015) Conjunctively screening of biocontrol agents (BCAs) against fusarium root rot and fusarium head blight caused by Fusarium graminearum. Microbiol. Res 177:34-42 
Wei W (2012) The suppressiveness caused by long-term continuous cropping of soybean on the root rot and pathogens. http://cdmd.cnki.com.cn/Article/CDMD-80062-1012032157.htm

Wei W, Xu YL, Zhu L, Zhang SL , Li S (2014) Impact of long-term continuous cropping on the Fusarium population in soybean rhizosphere. Chin. J. Appl. Ecol 25:497-504

Wending R (1932) Trichodema lignorum as a parasite of other soil fungi. Phytopathology 22:837-845

White TJ, Bruns TD, Lee SB , Taylor JW (1990) Amplification sand direct sequencing of fungal ribosomal RNA genes for phylogenetics. PCR Protoc 18:315-322

Yang F, Wang XC, Liao DP, Lu FZ, Gao RC, Liu WG et al (2015) Yield response to different planting geometries in maize-soybean relay strip intercropping systems. Agron. J 107: 296-304

Zhang JX, Xue AG, Cober ER, Morrison MJ, Zhang HJ, Zhang SZ et al (2013) Prevalence, pathogenicity and cultivar resistance of Fusarium and Rhizoctonia species causing soybean root rot. Can. J. Plant Sci 93:221-236

Zhang Y, Tian C, Xiao JL, Wei L, Tian Y, Liang ZH (2020) Soil inoculation of Trichoderma asperellum M45a regulates rhizosphere microbes and triggers watermelon resistance to Fusarium wilt. AMB Expression 10:pp.1-13

Zhou XG, Yu GB , Wu FZ (2011) Effects of intercropping cucumber with onion or garlic on soil enzyme activities, microbial communities and cucumber yield. Eur. J. Soil Biol 47: 279-287

\section{Figures}




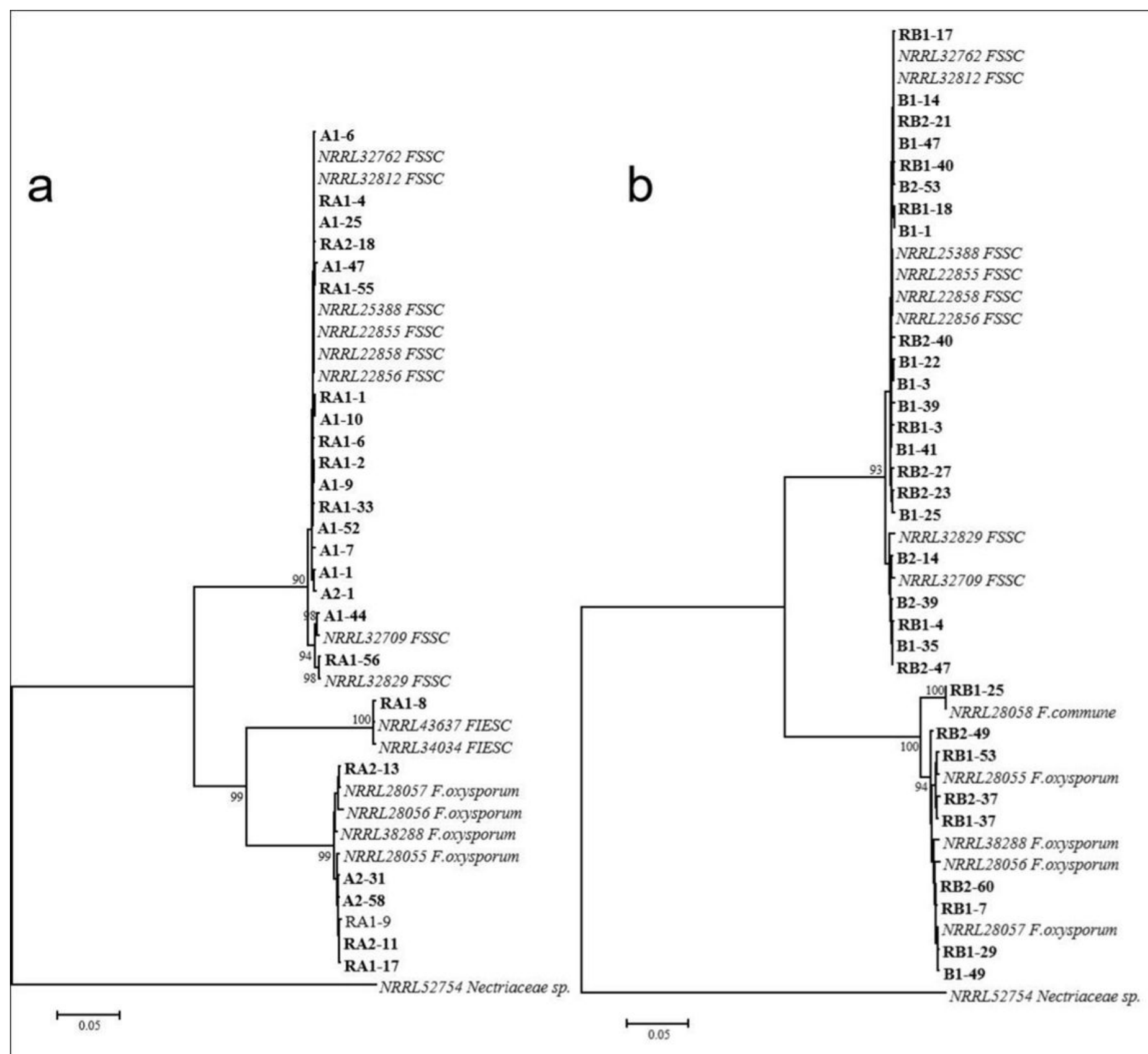

Figure 1

Intercropping were absolutely classified into 3 clades including FSSC, FIESC, and F. oxysporum in this tree constructed based on EF-1a and RPB2 (Figure 1A), while those isolates from monoculture were claded into FSSC, F. oxysporum and F. commune, respectively (Figure 1B), displaying a distinct species composition of Fusarium between intercropping and monoculture. 


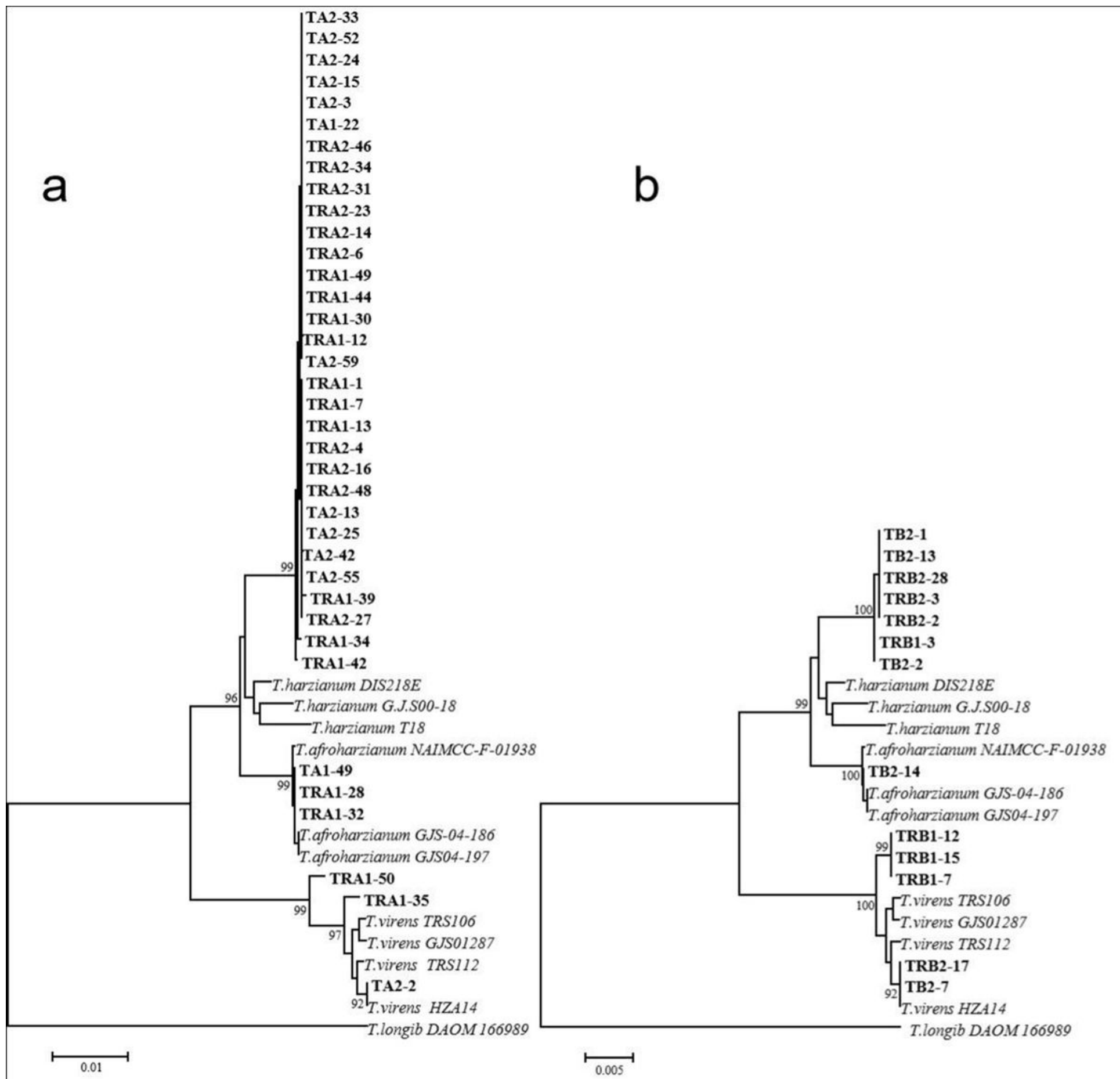

Figure 2

For phylogenetic analysis in Figure 2, all representative isolates from either intercropping or monoculture were clearly claded intro T. harzianum, T. virens, and T. afrohazianum, respectively in the ITS/RPB2-based MP trees with $\geq 99 \%$ the boostrap support value, whereas T. harzianum and T. afroharzianum were not totally discriminated in the ITS/EF-1a-based phylogenetic trees in both cropping patterns 
a

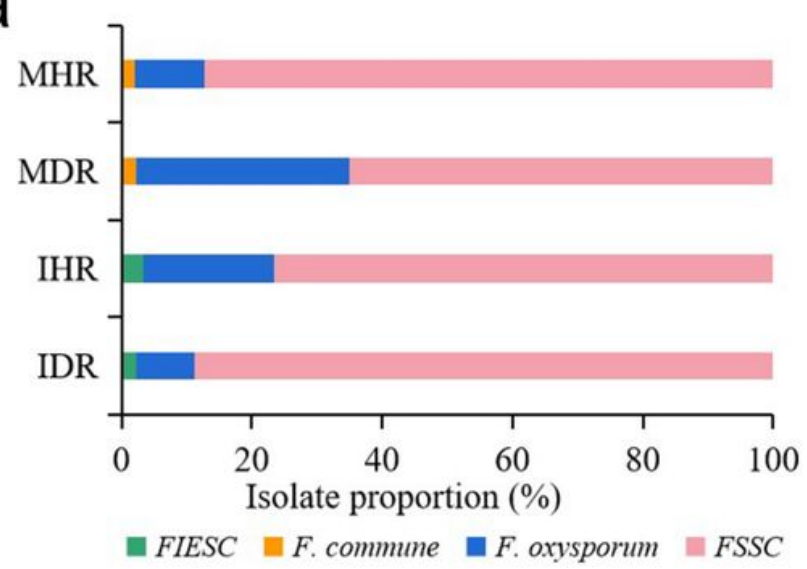

C

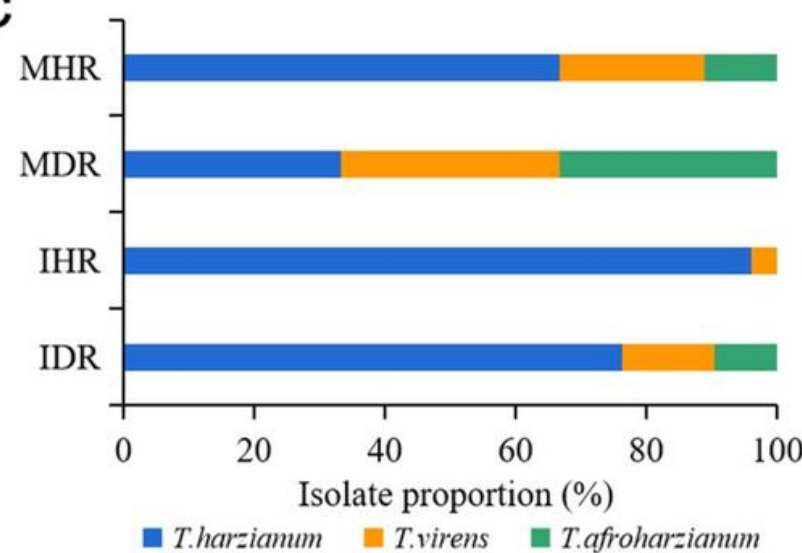

$\mathrm{b}$

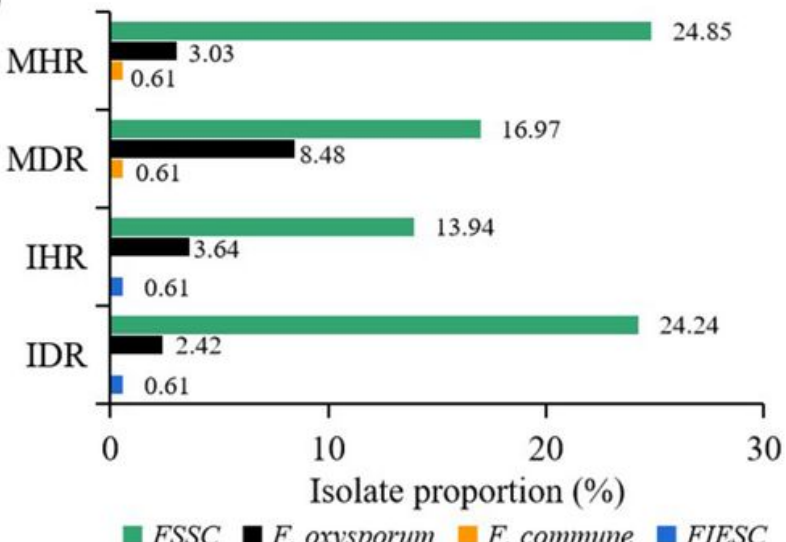

d

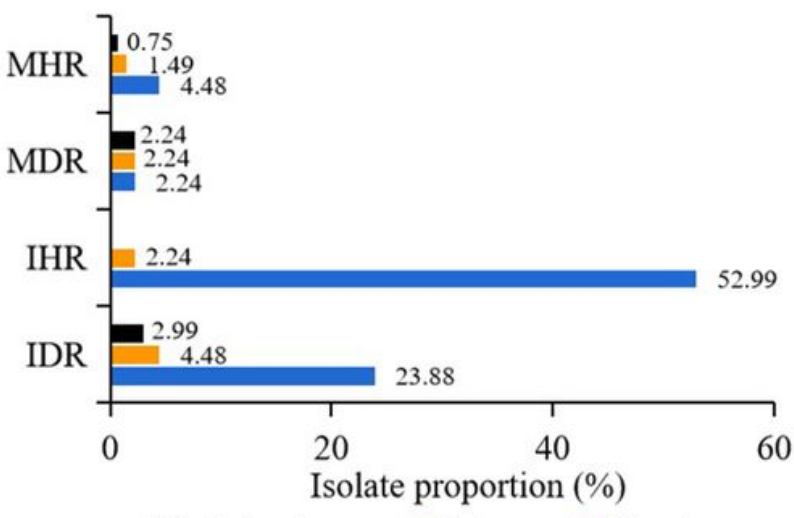

T.afroharziammm T.virens $\square$ T.harziamum

\section{Figure 3}

$3 \mathrm{~A}$ and $3 \mathrm{~B}, \mathrm{FSSC}$ had the highest isolation proportion in all soil types that reached up to $88.89 \%(40 / 45)$ of Fusarium composition and $24.24 \%$ (40/165) of all isolated Fusarium in IDR as compared to $65 \%$ (28/43) and $16.97 \%(28 / 165)$ in MDR (Figure 3A and 3B), respectively. 

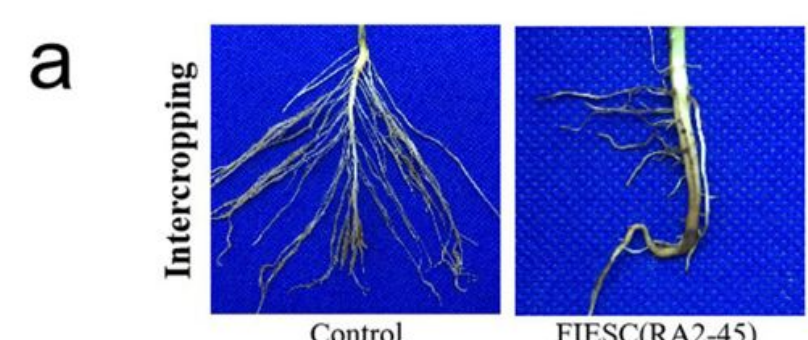

FIESC(RA2-45)
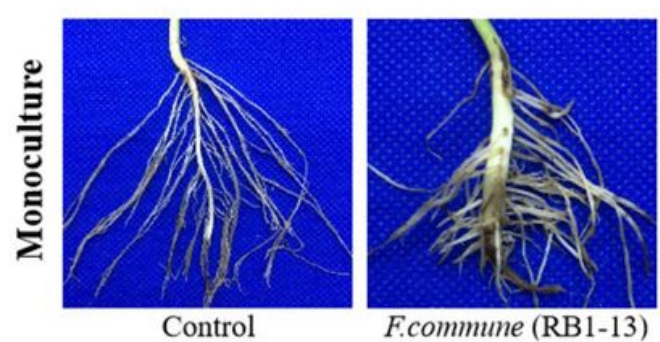

Intercropping
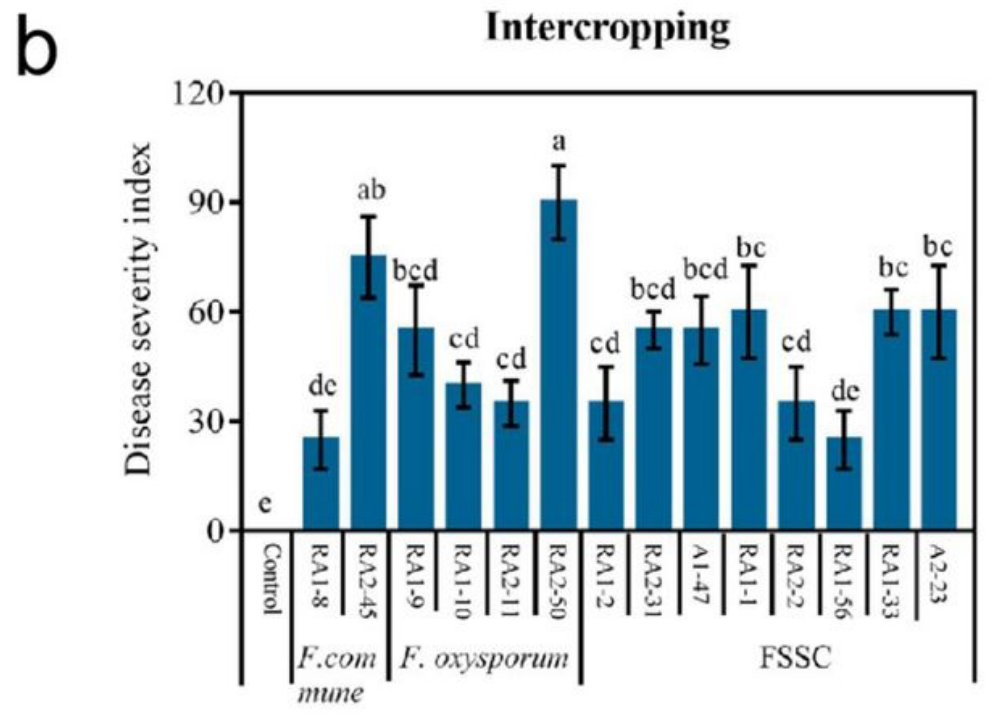

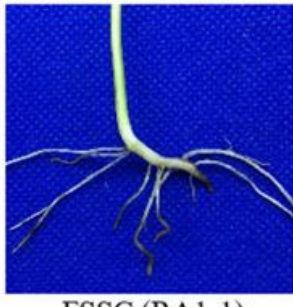

FSSC (RA1-1)
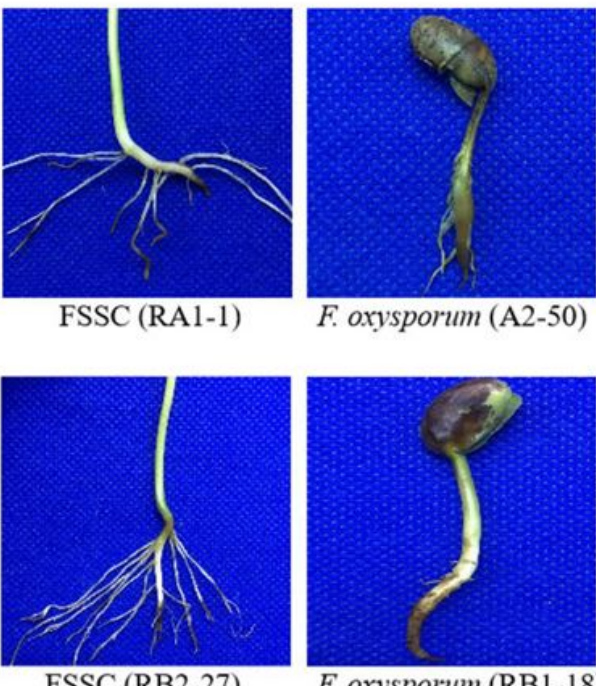

FSSC (RB2-27)

F. oxysportum (RB1-18)

\section{Monoculture}

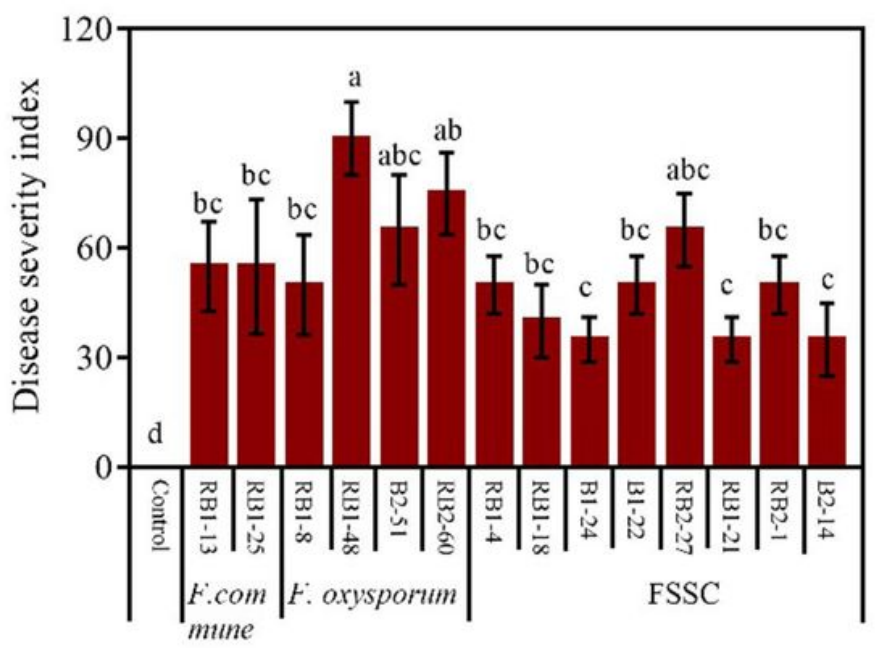

Figure 4

Pathogenicity test of rhizosphere Fusarium species on soybean seedling showed that all four Fusarium species were able to infect soybean roots, and cause stunted, brown, rotted taproots and hair roots but displayed significantly different aggressiveness 
a
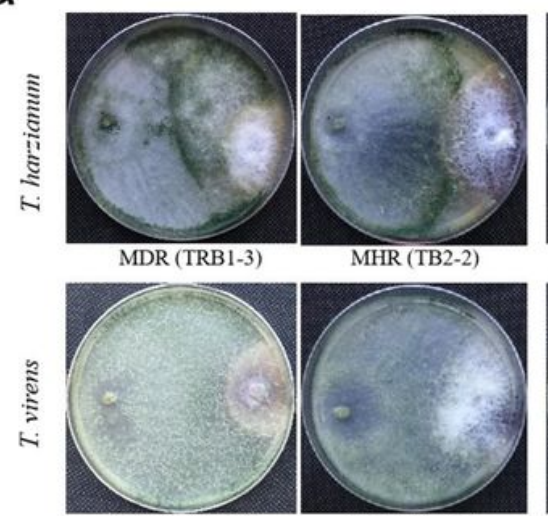

MDR (TRB1-15)

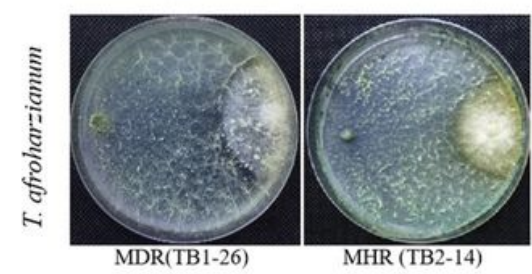

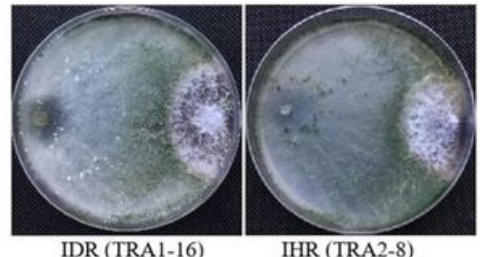

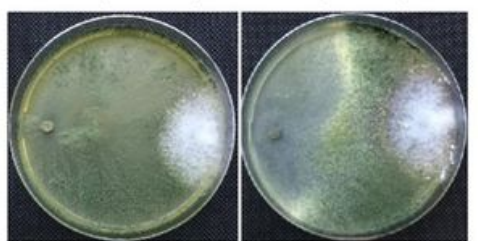

IDR (TRA1-35)

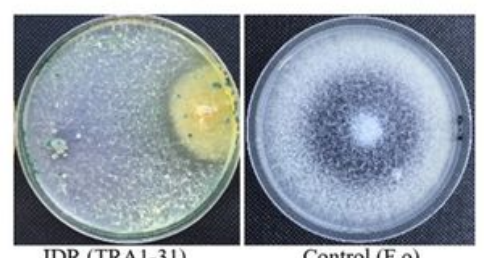

b

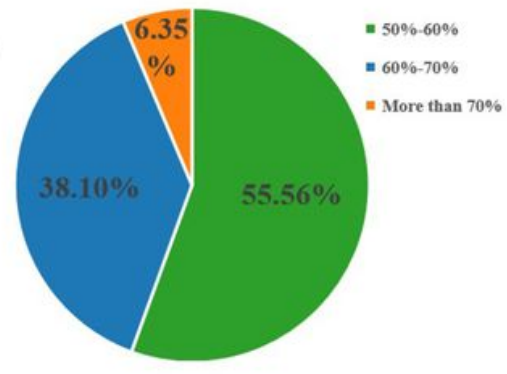

$\mathrm{C}$

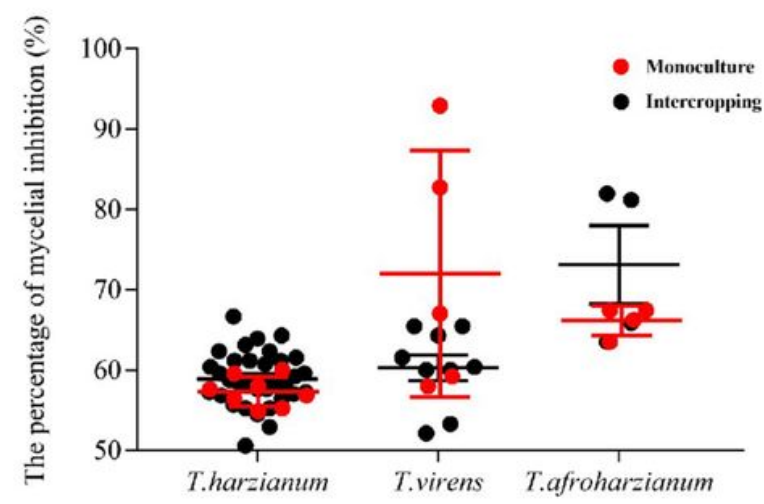

Figure 5

As compared to the F. oxysporum control, the representative isolates of three Trichoderma species grew tropically towards F. oxysproum and significantly inhibited mycelial growth of F. oxysporum through spatial competition on PDA confrontation culture plates 

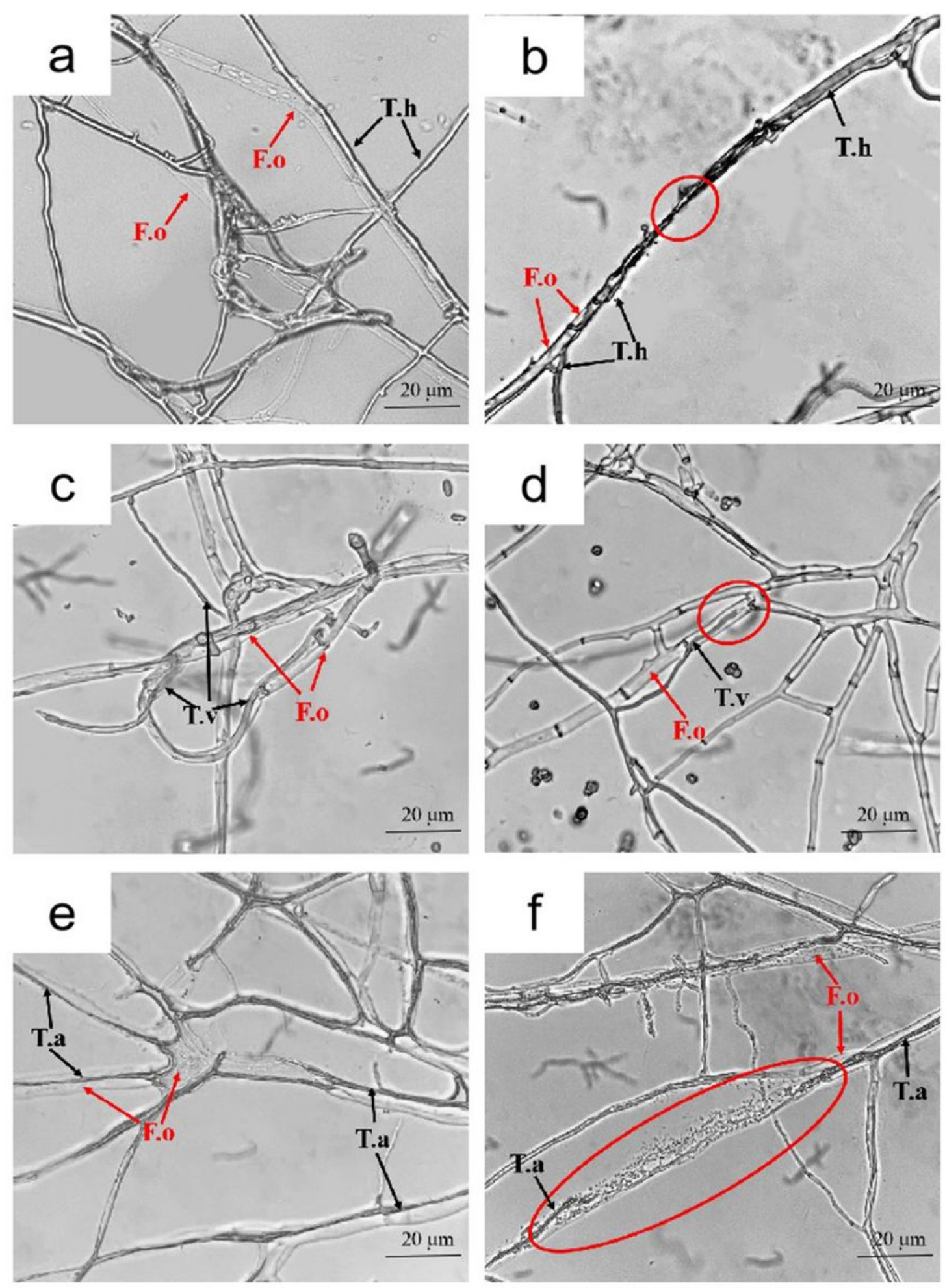

\section{Figure 6}

To observe the hyphae interaction, T. harzianum grew tropically towards (Figure 6A), attached to the hyphae of F. oxysporum, and coiled around them (Figure 6B). The strains TRB1-15 and TRB1-7 of T. virens coiled around the hyphae, formed brown halos at the contact sites (Figure 6C), and some of them directly entered into the lumen of the target fungus (Figure 6D). 


\section{Supplementary Files}

This is a list of supplementary files associated with this preprint. Click to download.

- Supplementarymaterials.rar 